\title{
Las Sociedades Patrióticas gaditanas (1820-1823)
}

\section{JOSÉ M.a GARCÍA LEÓN}

La costumbre de la tertulia y del café constituyó un fenómeno muy peculiar en Cádiz desde los primeros años del siglo XIX. A las tertulias, que se caracterizaron por un ambiente íntimo y familiar, es inevitable asociar el café que, como típico centro de reunión, vino a ser lugar de conspiraciones y conciliábulos conforme las ideas liberales fueron conformándose.

A principios de siglo, el café era ya en Cádiz una institución que gozaba de una gran popularidad y al que se iba no sólo a consumir bebidas, sino a intercambiar opiniones, conversar y leer periódicos y folletos. Antes de 1820 destacaron, entre otros, los cafés de Cossi y el de las "Cádenas", escenario ambos de las disputas entre los partidarios y detractores de la Constitución de 1812. Después de la guerra de la Independencia, los cafés de la "Horta" y de "Apolo" fueron los principales centros de reunión, aunque mediatizados por la reacción fernandina contra los liberales (1).

A raíz del pronunciamiento de 1820 , que trajo como consecuencia la implantación del régimen constitucional, todos aquellos que quisieron propagar sus ideas en orden al nuevo régimen, hallaron su cauce de expresión más adecuado en las Sociedades Patrióticas que, por su parte, suponen una de las instituciones más típicas del llamado Trienio Liberal. La existencia de estas sociedades es vital para comprender bien los sucesos cotidianos, así como la evolución de las mentalidades en estos años, destacando, sobre todo, una finalidad divulgadora destinada, al decir de Alberto Gil Novales, "a difundir las ideas liberales y el significado de la Constitución a capas cada vez más amplias del pueblo» (2). $\mathrm{Ni}$

(1) En el proceso que se siguió contra el café de Apolo, acusado de foco de conspiradores, el juez expuso que en él "se trató de formar y formó una Asociación, con presidente y secretario, a semejanza de la que se dijo existió en los Estados Unidos, para tratar los asuntos públicos». Cfr. Juan NAVARRO LA TORRE, El Café de Apolo, Cádiz, 1974, p. 15 .

(2) Cfr. El Trienio Liberal, Madrid, 1981, p. 11. 
que decir tiene que, para los elementos liberales, fueron un gran medio para sus fines propagandísticos (3).

\section{DE LAS SOCIEDADES ECONÓMICAS A LAS SOCIEDADES PATRIÓTICAS}

Un curioso precedente de estas nuevas sociedades fueron las Sociedades Económicas de Amigos del País, típica creación del siglo XVIII. Con el transcurrir del tiempo, estas sociedades cambiaron su sentido para pasar a ser centros de actividad casi exclusivamente política, aunque, más que de una política activa, fueron lugares de discusión y de información mutua.

A poco de instaurarse el régimen liberal, La Gaceta Patriótica del Ejército Nacional, órgano de propaganda del ejército sublevado y que respondía a la inspiración de Alcalá Galiano y Evaristo San Miguel, tras señalar que la constitución de Sociedades Patrióticas había comenzado en toda España, hacía un público llamamiento a los gaditanos para que se animaran a crear alguna en la ciudad. Ponía como ejemplo la madrileña del café de Lorencini. Más aún, si se tenía en cuenta que, en tiempos pasados, ya había habido una en Cádiz, "tan sonada, que mereció al Conde de Abisbal que purificase el sitio en que recurría haciéndolo cuerpo de guardia". Indudablemente se estaba refiriendo al desaparecido café de "Apolo" (4).

Pero con la llegada del Trienio conviene insistir en una cuestión que puede llevarnos a confusión y que es preciso que aclaremos. En estos momentos de la nueva andadura constitucional, marzo y abril de 1820 , en plena exaltación liberal, el adjetivo "patriótico" se aplicaba por doquier a las instituciones más diversas. Así pues, en tal sentido, las Sociedades Económicas no fueron una excepción. Efectivamente, en Cádiz, con fechas de 6 y 8 de abril de 1820 aparecen sendos documentos en los que se cita el calificativo de Sociedad Patriótica, pero con la adición de "Amigos del País", lo cual nos hace pensar que, tal vez, sea un cambio de denominación de las antiguas Sociedades Económicas ante la nueva situación política.

(3) Iris M.`ZAVALA, Masones, Comuneros y Carbonarios. Madrid, 1971, pág. 59. Véase también Aberto GIL NOVAlES, obicit.

(4) Este llamamiento no deja de ocultar sus dosis de ironía, al concluir diciendo: "establézcase de nuevo allí o en otro punto, que ya estamos avisados y no hay temor que vengan nuevos condes a purificar tan extrañamente", cfr. Gaceta Patriótica del Ejército Constitucional, núm. 23, 11 abril 1820. 
Se optó, pues, por una solución salomónica, al enlazar ambos conceptos en una sola expresión. En uno de estos documentos, el Ayuntamiento decide cederle a la Sociedad, recientemente constituida, la sala capitular para que prestara juramento (5). En el otro hay un ofrecimiento al Ayuntamiento, poniendo a su disposición todos sus conocimientos $y$ trabajos (6).

\section{TRAYECTORIA}

Gran controversia presentó en 1820 la legalización de estas sociedades, pues la comisión encargada de la redacción del proyecto se declaró hostil a ellas, por el temor de estar frente a una repetición de los clubs jacobinos de la revolución francesa. De ahí, las constantes referencias que se hicieron a nuestro pasado histórico, haciéndose hincapié, sobre todo, en las asociaciones medievales, como argumentó apasionadamente Martínez Marina (7). De forma muy parecida se pronunció Alvaro Flórez Estrada, quien, en su intento de justificación histórica, se remitió hasta las Hermandades castellanas (8).

Alcalá Galiano, que habló varias veces en la Fontana de Oro, en la Sociedad de Córdoba y en la de Cádiz, como juicio global, saca la conclusión de que eran una especie de tertulias en las que, la mayor parte de las veces, las intenciones del orador iban en sentido contrario a las del público. Esto dio pie para que las opiniones sobre un determinado tema alcanzasen las tonalidades más diversas. No puede expresarse de forma más gráfica, cuando nos dice que «el orador hacía las veces el papel de algún músico que toca o canta a un auditorio que le presta poca atención o ninguna» (9).

El marqués de Miraflores tampoco puede darnos una apreciación más peyorativa al calificar de "asquerosas" sus reuniones, que no eran sino "una copia servil de los clubs del año 1789 en Francia" y, al referirse a los asiduos de los cafés de Lorencini y de San Sebastián, no duda

(5) Actas. Cabildo Municipal, cabildo ordinario núm. 14, 8 abril 1820.

(6) A.C.M., c, or. núm. 13, 6 abril 1820.

(7) José Antonio MARAVALL, "El pensamiento de España a comienzos del siglo XIX:

(8) Discurso de Flórez Estrada. En Estudios Políticos, núm. 81, Madrid, 1955, p. 43. obra de Juan RICO Y AMAT, El libro de las Sociedades Patrióticas, recogido en la t. I, p. 165.

(9) Cfr. Recuerdos de un Anciano, O.E., t. LXXXIV, Biblioteca de Autores Españoles,
Madrid, 1955, p. 164. 
en calificarlos como «la hez de la sociedad» (10). En cambio, para Evaristo de la Escalera representan un elemento positivo y necesario, reconociéndoles un gran influjo en la sociedad, a la vez que arremete contra los elementos reaccionarios "que denominaban excesos de la anarquía a la natural expansión de la libertad» (11).

No tardaron estas sociedades en proliferar por todo el país, siendo las primeras, o al menos, las más conocidas, las madrileñas de San Sebastián, la de Lorencini, la Cruz de Malta y la Fontana de Oro. En cambio, la vida de estas sociedades en provincias no tuvo un impulso suficiente y carecieron de las posibilidades que las cercanías del poder pudo proporcionar.

El ya citado Gil Novales, que ha estudiado exhaustivamente el fenómeno de las Sociedades Patrióticas, señala tres fases en su trayectoria, perfectamente aplicables al caso gaditano:

1.-Primer período, desde los orígenes hasta la Ley de las Cortes de 21 de octubre de 1820 , promulgada por el Rey el 8 de noviembre.

2.-Segundo período, Tertulias Patrióticas, desde 1821 hasta el magno suceso de julio de 1822 (rebelión de la guardia de Palacio).

3.-Tercer período, Sociedades Patrióticas, desde esta fecha hasta la caída del régimen constitucional (12).

\section{LAS PRIMERAS SOCIEDADES PATRIÓTICAS GADITANAS}

Parece ser que la primera Sociedad se inauguró en abril de 1820, en el antiguo café del Correo, rebautizado ahora con el nombre «La Constitución". Estaba regentado por Francisco de Celis, que venía anunciando, como forma idónea de propagación de las ideas liberales, el poner una especie de tribuna en su establecimiento, la cual estaría a la disposición de todos aquellos que quisieran lanzar arengas y discutir sobre asuntos políticos preferentemente. Sobre el origen de estas sociedades, el propio Celis no dudó en utilizar argumentos, más o menos convincentes, que le hicieron remontarse a la democracia griega e invocar a Sócrates y a Demóstenes (13).

(10) Apuntes histórico críticos para escribir la Historia de la Revolución de España, desde el año 1820 hasta 1823, Londres, 1834, pág. 50.

(11) Cfr. Evaristo de la ESCALERA y Manuel GONZÁLEZ LLAMA: La España del siglo XIX, Madrid, 1864, p. 383.

(12) Tomando los casi cuatro años en conjunto ha podido constatar la existencia de Sociedades Patrióticas en 164 poblaciones. Ob. cit., p. 13.

(13) Adolfo DE CASTRO, Cádiz en la guerra de la Independencia, Cádiz, 1864, p. 145. Véase también, A.C.M., c. or. núm. 69, 29 julio 1820. 
El 16 de abril se inauguró formalmente en una sesión con' gran cantidad de público (14). En su reglamento se previó la existencia de un director, dos secretarios y seis oradores. Como objetivos principales quedaron señalados el comentar las sesiones de las Cortes, así como la explicación cada noche de los artículos de la Constitución, y el cambio de impresiones sobre las incidencias políticas más dignas de ser destacadas.

Todo el reglamento deja traslucir ese espíritu transigente y tolerante, muy propio de estos momentos, no exento de candor y vehemencia, plasmados en advertencias tales como que no se podía interrumpir al que estuviera en el ejercicio de la palabra (art. XVI), o no se debíá entrar' en la vida privada de los ciudadanos, aunque «se podía censurar la pública de los magistrados y de todos los que ejercen cualquier autoridad" (art. XVII). No obstante, había que guardar las formas y hasta un estricto rigor en aspectos tan pintorescos, si bien no exentos de razón, como las prohibiciones de fumar y llevar el sombrero puesto mientras durasen las sesiones (15).

Esta sociedad debió durar poco tiempo, apenas un mes. Lo cierto es que el 15 de mayo se inauguró allí mismo una nueva, cuyo título definitivo fue el de "Sociedad Gaditana de Amigos del hombre». Estuvo presidida por el exdiputado por Cádiz en 1814, Manuel López Cepero. Otra sociedad cuya existencia también hemos podido constatar, en estos momentos iniciales del Trienio, fue la del «Café del Rey Constitucional", situada en la plaza de la Constitución. Su dueño, bajo las iniciales de M.R. hizo una llamada a través del Diario Mercantil para constituirla; cifró en 120 el número de sus futuros componentes. Pero ni siquiera hay constancia de que llegase a constituirse. En adelante, el protagonismo en este tipo de establecimientos iba a corresponder, casi exclusivamente, al Café Constitucional (16).

A nivel nacional es evidente que cada vez iba siendo mayor el protagonismo de las Sociedades Patrióticas en este tipo de polémicas. Vicente de la Fuente señaló la campaña que la Fontana de Oro, bajo el título de Sociedad de los Amigos del Orden, vino haciendo sobre la opinión pública madrileña, ya que, por medio del derecho de petición, se había lanzado a todo tipo de reclamaciones. Por cierto, que entre los

(14) "Sesión del día 16 de abril de 1820, de la Sociedad Patriótica del café de la Constitución". Documento interpolado en la colección del Diario Mercantil de Cádiz, año
1820 , núms. 1.352 y 1.353 .

(15) Adolfo DE CASTRO, Historia de Cádiz y su provincia, t. II, edic! 1982, Cádiz, p.
211 .

(16) D.M.C., núm. $1.354,18$ abril 1820. 
"más charlatanes», cita a Alcalá Galiano, «entonces de mediana reputación" (17).

Los sucesivos acontecimientos, entre ellos la disolución del ejército de la Isla, provocaron la decisión del Gobierno de clausurar todas las Sociedades Patrióticas. En Cádiz, el 8 de diciembre, se publicaba el decreto, fecha 8 del mes anterior, por el que se prohibían «las sociedades, confederaciones y juntas patrióticas, con arreglo a las leyes que prohíben estas corporaciones" (18). Sin embargo, nos engañaríamos si creyéramos que la inquietud ciudadana, con las consiguientes manifestaciones de las que solía hacer gala, iba a desaparecer.

Con la clausura de las Sociedades Patrióticas a finales de $1820 \mathrm{cul}-$ minaba su primera etapa. En ella se había puesto de relieve la influencia de estas sociedades en una opinión pública cada vez más sensibilizada ante los acontecimientos políticos y que, desde el primer momento, había empezado a intuir que, aun aceptando el Rey la Constitución, en el seno de importantes sectores de la nación, entre ellos la propia Monarquía, se escondía un vivo deseo de acabar con el sistema o, cuando menos, de desvirtuarlo (19).

El 27 de febrero de 1822, un grupo de 117 ciudadanos había enviado una petición a las Cortes, en la que se solicitaba el restablecimiento de las Sociedades Patrióticas «bajo reglamentos fijos», siempre y cuando se hicieran compatibles "con la libertad civil». El consiguiente decreto fue leído el 13 de abril y, salvo alguna que otra enmienda, fue presentado al Rey "quien ofreció tomarlo en consideración" (20). Pero Fernando VII, consultado el Consejo de Estado, decidió no sancionar este decreto, decidiendo que permaneciera "en su fuerza y vigor la ley sobre Sociedades Patrióticas de 22 de octubre anterior" (21).

Las razones, leídas por el ministro de la Gobernación, venían a expresar los recelos del Rey ante la posibilidad de que volvieran a repetirse desórdenes. Se señalaba también que no había garantía alguna de ofrecer los medios suficientes para evitar las alteraciones del orden. En este razonamiento negativo, era inevitable la significativa pregunta sobre qué sentido podían tener estas sociedades, si se tenía en cuenta que regía una Constitución que «aseguraba la libertad con más garantía que ninguna

(17) Vicente DE LA FUENTE, Las Sociedades Secretas, t. I, Madrid, 1874, p. 22.

(18) A.C.M., c. or. núm. 135, 9 diciembre 1820.

(19) "Letrillas", La Ciudadana Constitucional, Madrid, 1820, B.T.G. c/20, f/1.

(20) El decreto tan sólo había recibido unos leves retoques con las enmiendas del diputado Zorraquín en los artículos $2 .^{\circ}$ y $6 .^{\circ}$. "Sesión del 13 de abril". Diario de Decretos, Legis, 1820-1821, t. XV, p. 6.

(21) "Sesión del 12 de mayo". Diario de Decretos, t. XVII, p. 43. 
de las que se conocen en Europa» (22). Así pues, el decreto, vista su inviavilidad, fue archivado con el enterado de las Cortes.

\section{ÚLTIMA APARICIÓN DE LAS SOCIEDADES PATRIÓTICAS}

Con la llegada del régimen exaltado del gobierno de San Miguel, a raíz de los sucesos de julio de 1822, surgieron de nuevo las Sociedades Patrióticas, esta vez bajo un ambiente más propicio. Sin embargo, ya no volvieron a tener una reglamentación tan favorable como en 1820 . El 17 de octubre de 1822 se presentó un proyecto de ley en las Cortes en el que se pedía el restablecimiento de estas Sociedades. Dicho proyecto, con muy pocos retoques, fue aprobado con el título de «Ley que prescribe las formalidades con que las personas pueden reunirse en público para discutir materias políticas" (23).

A raíz de esta ley, pronto volvieron a proliferar por todo el país estas reuniones, sin dejar de sufrir los ataques de quienes veían en ellas focos de agitaciones y tumultos. En Cádiz, el 25 de octubre, el jefe político, por medio de una circular, pedía a los alcaldes de los pueblos de la provincia que promovieran la formación de Sociedades Patrióticas "por todos los medios que estuviesen a su alcance", y el propio Ayuntamiento gaditano proponía al obispo que se restableciera una tribuna patriótica en la iglesia de San Antonio (24).

El 2 de enero de 1823, ante los rumores y sospechas de una intervención extranjera en los asuntos españoles, los concurrentes de la nevería "La Rosa Constitucional", en la que se había formado una reunión patriótica, salieron por la noche en procesión, con banda de música y portando el retrato de Riego y un ejemplar de la Constitución. Posteriormente, cuando la crisis de febrero de 1823, en la que Fernando VII optó por querer variar el Gobierno, en la nevería se pidieron firmas al público para que el Rey reconsiderase su postura (25).

Gil Novales señala que hubo otro intento de constituir una nueva Sociedad, según idea de Díaz de Morales, que quedaría como presidente. Contaba con hombres como Santiago Jonama, Vega y Ceruti (26). En los meses siguientes, conforme la situación política se iba deteriorando cada vez más, en Cádiz se fue hacia una política de represión de

(22) Ibídem, p. 46.

(23) Colección de decretos $y$ órdenes, expedidos por las Cortes Extraordinarias que corresponde desde el 3 de octubre de 1822 hasta el 13 de febrero de 1823, t. X, Madrid, 1823.

(24) A.C.M., c. ex. núm. 163, 31 octubre 1822.

(25) D.M.C., núm. 2.399, 28 febrero 1823.

(26) Ob. cit., p. 416. 
las libertades, que culminan con el cierre del café de la Victoria, del que el Diario Mercantil de Cádiz decía que servía de refugio para los que «alteraban la tranquilidad pública», presentándolo como un peligroso foco comunero (27).

\section{INFLUENCIA POPULAR}

Popularmente, las Sociedades Patrióticas ejercieron un gran influjo, y fueron tribuna donde se dirimieron los asuntos más dispares, aunque todos ellos tuvieron como denominador común la inquietud ciudadana y una especial sensibilidad por los temas a tratar.

Como ejemplo significativo tenemos el asunto de Lluelles, antiguo colaborador del coronel Rotalde, que fue acusado por éste de no tener muy claras las cuentas del dinero que le fue confiado por los revolucionarios cuando prepararon la fallida intentona del 24 de enero de 1820. Como la cuestión amenazaba con convertirse en un escándalo de considerables repercusiones, y la propia imagen de Lluelles podía quedar bastante comprometida, éste hizo una súplica a los que formaban «alguna de las Sociedades Patrióticas establecidas en Cádiz» (28), para que esclarecieran el hecho y se nombrara una comisión, cuyo juicio, favorable o no, el interesado estaba dispuesto a acatar, previamente comunicado a la opinión pública. Con este gesto tan significativo, se dio un voto de confianza a la labor de las sociedades, en particular a la del "Café de la Constitución", que ya había empezado a interesarse por este litigio (29).

Alcalá Galiano, para quien estas Sociedades no pasaron de ser «necias o insulsas", peroró dos o tres veces en la de San Fernando y, en una sola sesión, en la del "Café Constitucional», en la que despertó "más desaprobación que aplauso", al abordar el muy espinoso tema de la independencia de las provincias americanas, de las que se mostró claramente partidario (30). Cuando se produjo el famoso decreto del 4 de agosto, por el cual el marqués de las Amarillas disolvió el Ejército de la Isla, la indignación popular subió desmesuradamente de tono. Ya el 16 de mayo se envió una comunicación a Fernando VII pidiéndosele la separación del citado marqués del ministerio de la Guerra, pues siempre se desconfió de él desde las posiciones más liberales (31).

(27) Gaceta Española, Cádiz 2 julio 1823, sesión del día 1.

(28) El ciudadano Lluelles a los que hayan leído el primer apéndice al manifiesto de Rotalde, Cádiz, 1820, p. 1.

(29) Ibídem, p. 4.

(30) Recuerdos, ob. cit., p. 152.

(31) Alberto GIL NOVALES, El Trienio... ob. cit., p. 9. 
No es de extrañar esta forma de proceder, pues los habituales de los cafés y tertulias patrióticas solían ir con frecuencia a Palacio a manifestar sus quejas y pareceres. El propio marqués de las Amarillas dejó ver su malestar por la intromisión de la que era objeto en un asunto como la disolución de este ejército, que siempre consideró como una cuestión de tipo técnico, propia sólo de las competencias de su ministerio. Asimismo, no ocultó su desconfianza por las Sociedades Patrióticas, a las que, evidentemente, no podía ver con muy buenos ojos. Así, de forma irónica, juzgó a la tribuna del café de Lorencini, "de la que fueron oradores un albañil, algún oficial retirado y otros de clase y ocupación ignorados" (32).

Actitudes semejantes se registraron en Cádiz cuando la revuelta urbana de 1821 , la ya mencionada agitación política que se vivió a raíz de los sucesos de julio de 1822 y, finalmente, con las manifestaciones de todo tipo que se produjeron en pleno estertor del régimen constitucional, a partir de febrero-marzo de 1823.

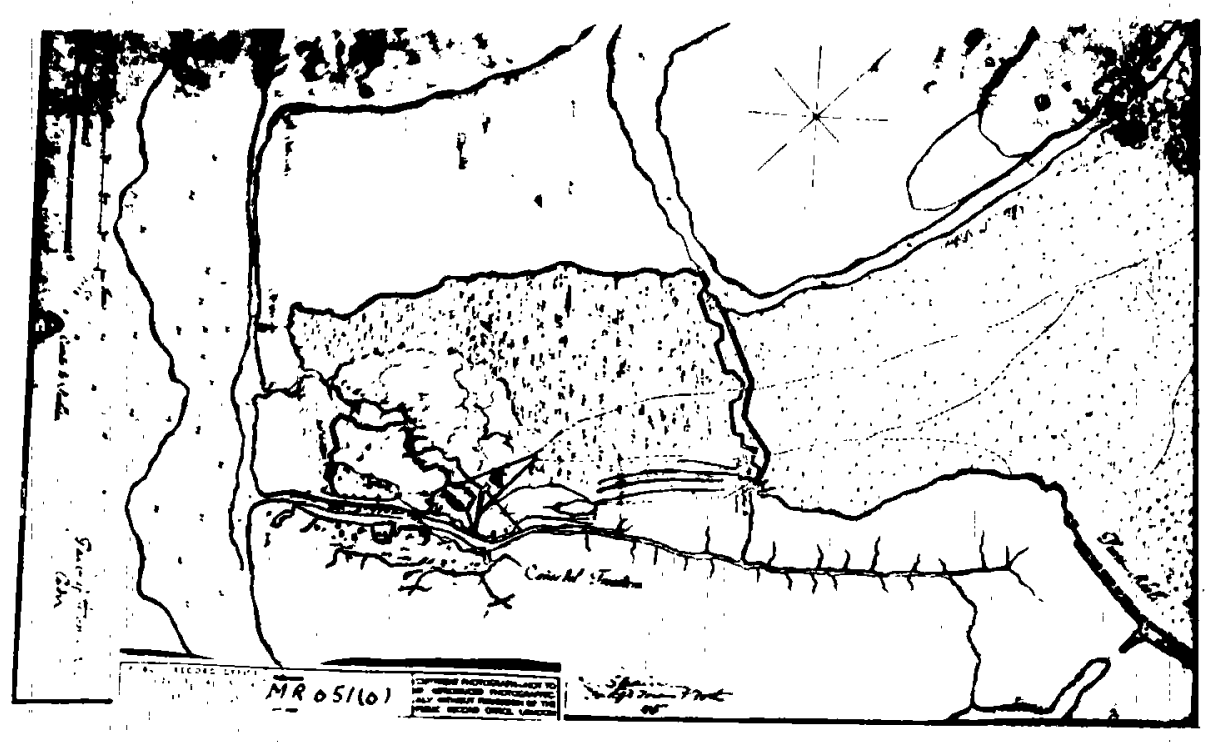

Plano de las defensas del Caño del Trocadero en Cádiz en los comienzos del siglo XIX.

(32) Juan ARZADUN, Fernando VII y su tiempo, Madrid, 1942, p. 141. 


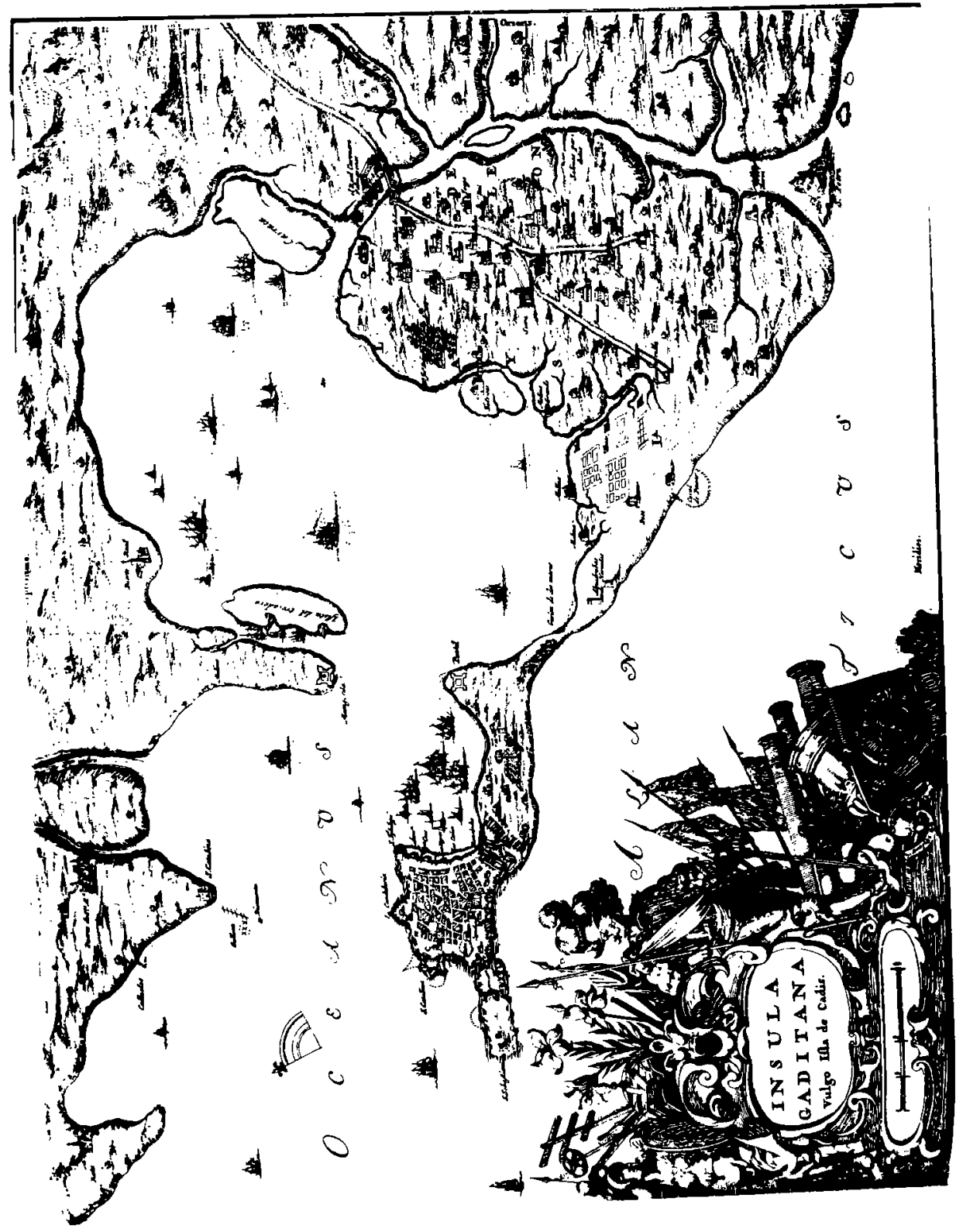

